\title{
SUBFORNICAL ORGAN-MEDIAN PREOPTIC CONNECTIONS AND DRINKING AND PRESSOR RESPONSES TO ANGIOTENSIN II $^{1}$
}

\author{
R. WALLACE LIND ${ }^{2}$ AND ALAN KIM JOHNSON
}

The Department of Psychology and The Cardiovascular Center, The University of Iowa, Iowa City, Iowa 52242

Received December 17, 1981; Revised April 16, 1982; Accepted April 29, 1982

\begin{abstract}
The subfornical organ (SFO) and the periventricular tissue of the anteroventral third ventricle (AV3V) have been shown to be important for the central action of circulating angiotensin. Recent anatomical findings have elucidated neural connections between the SFO and several structures within the AV3V region. The present study examined the function of fibers between the SFO and the median preoptic nucleus.

Horizontal knife cuts rostral to the anterior commissure severed precommissural fibers between the SFO and the median preoptic nucleus. Cuts immediately dorsal to the anterior commissure interrupted both pre- and postcommissural connections. Rats with cuts of both sets of fibers evidenced a virtual absence of drinking responses following subcutaneous injections of angiotensin, while rats with selective cuts of precommissural fibers manifested a partial, but significant, reduction in responding. The two groups of animals showed similar attenuations in drinking responses following subcutaneous injections of hypertonic saline. Rats with cuts of both pre- and postcommissural fibers evidenced an attenuation of drinking responses elicited by centrally administered angiotensin. Pressor responses following intravenous and intraventricular angiotensin injections were not reduced specifically by the experimental knife cuts.

These findings are consistent with a model that postulates that angiotensin receptors, and perhaps osmoreceptors, in the SFO send excitatory neural information to the median preoptic nucleus for the mobilization of thirst.
\end{abstract}

Angiotensin of peripheral origin stimulates receptors in the central nervous system for the initiation of compensatory reactions to fluid loss. While the area postrema is an important receptor in many species, it appears to be of minor importance in the rat (Simpson, 1981). In this animal, the subfornical organ (SFO) has received the most support as the locus of central receptors for circulating angiotensin.

The initial studies implicating the SFO demonstrated that injections into this structure elicit thirst (Simpson and Routtenberg, 1973) and that its electrolytic ablation abolishes the dipsogenic properties of peripherally administered angiotensin (Abdelaal et al., 1974; Simpson

\footnotetext{
' This research was supported by United States Public Health Service Research Grants HLP-14388 and 1 R01 HL24102, Physiological Psychology Training Grant 1 T32 MH 15773, and National Institute of Mental Health Research Scientist Development Award 1 K02 MH 00064. We thank Becky Rowe for secretarial assistance, Robert Russell for help in making the knife cut device, and Dan Tranel for invaluable instruction in the use of computerized statistical programs.

${ }^{2}$ To whom correspondence should be addressed at The Salk Institute, P.O. Box 85800, San Diego, CA 92138.
}

and Routtenberg, 1975). In contrast, several studies indicate that intraventricularly applied angiotensin acts at receptors outside of the SFO (Buggy and Fisher, 1976; Findlay et al., 1980; Hoffman and Phillips, 1976; Thunhorst et al., 1981). However, the importance of this circumventricular organ for circulating angiotensin continues to be demonstrated (Findlay et al., 1980; Shrager and Johnson, 1980; Thunhorst et al., 1981). Particularly compelling is the finding that direct injections into the SFO of a competitive blocker attenuate thirst elicited by peripheral angiotensin (Simpson et al., 1978).

Recently, data have been reported which suggest that angiotensin receptors in the SFO participate in the control of blood pressure. Mangiapane and Simpson (1980a) describe an attenuation of the hypertensive effect of intravenous angiotensin in rats with electrolytic lesions of the SFO. In another paper, these authors (Mangiapane and Simpson, 1980b) report that injections into the SFO stimulate a short latency pressor effect that is independent of the drinking response.

The periventricular tissue of the anteroventral third ventricle, or "AV3V" region, also has received considerable attention for its role in mediating the pressor and 
dipsogenic actions of angiotensin (Brady and Johnson, 1980). The AV3V region consists of the subcommissural part of the median preoptic nucleus, the organum vasculosum of the lamina terminalis (OVLT), the periventricular preoptic nucleus, and the medial part of the medial preoptic area. It has been demonstrated that electrolytic destruction of these tissues blocks the drinking (Buggy and Johnson, 1977) and attenuates the pressor (Buggy et al., 1977) responses that result from peripheral administration of angiotensin. If it is the case that circulating angiotensin is detected by receptors in the SFO, the AV3V lesion effects cannot be due to the primary destruction of receptors. Recent neuroanatomical studies suggest, rather, that these effects may result from the removal of secondary neurons, the destruction of fibers of passage, or both.

Tracing work employing the injection of tritiated amino acids (Miselis, 1981; Miselis et al., 1979) and horseradish peroxidase (HRP) (Lind et al., 1982) into the SFO has identified a ventrally directed system of efferents that contacts structures throughout the AV3V region (see Fig. 1). Prominent among the areas receiving inputs from the SFO is the median preoptic nucleus, which receives primarily precommissural, but also some postcommissural, afferents. Grazi and Miselis (1980) and Lind et al. (1982) have verified the projection from the SFO to the median preoptic nucleus by labeling cell bodies in the SFO with HRP injections into the median preoptic nucleus. SFO efferents that pass through the median preoptic nucleus have been followed to the OVLT and to the suprachiasmatic and supraoptic nuclei by Lind et al. (1982).

Since recent findings demonstrate that selective lesions of the median preoptic nucleus diminish drinking responses to angiotensin (Lind et al., 1981a; Mangiapane et al., 1981), it was hypothesized that projections from the SFO to the median preoptic nucleus might carry information relevant to angiotensin-induced thirst. It has already been reported that rats with nearly total SFO deefferentations fail to drink when given peripheral injections of angiotensin (Lind and Johnson, 1980; Eng and Miselis, 1981). In the present study, rats with knife cuts of the precommissural fibers and others with cuts of both the precommissural and postcommissural connections between the SFO and the median preoptic nucleus were compared with control animals for responses to thirst and pressor stimuli. The results suggest that this ncural pathway plays an important role in mediating thirst that results from the peripheral administration of angiotensin and hypertonic saline. It may participate in the mediation of thirst induced by intraventricular angiotensin but does not appear to be important for pressor responses to angiotensin by the central or peripheral routes.

\section{Materials and Methods}

Subjects. Male Sprague-Dawley rats weighing between 300 and $400 \mathrm{gm}$ at the start of the experiment were kept in hanging wire cages with food (Teklad pellets) and water provided ad libitum except where noted. Temperature in the animal colony was maintained at approximately $22^{\circ} \mathrm{C}$. The $12: 12$ light:dark cycle began with lights on at 8:00 A.M.
Screening tests. At least 5 days after being singly housed in the vivarium, presurgery screening was conducted. All animals reccived a subcutaneous injection of angiotensin (Hypertensin, Ciba; $1.2 \mathrm{mg} / \mathrm{rat}$ ) and subsequent drinking responses were recorded for $1 \mathrm{hr}$ with water provided in modified chemical burettes. To be included in the study, animals had to drink at least 2.0 $\mathrm{ml}$ during the 60-min observation period. Initially, 104 rats were screened in this manner, and 71 passed the criterion on the first test. The 33 nonresponders were tested a second time, and 14 of them satisfied the criterion. The remaining 19 animals were discarded from the study.

Surgery. Standard stereotaxic procedures and ether anesthesia were used on all animals to produce a knife cut (or sham cut) and implant a lateral ventricle cannula in one continuous operation. About one-third of the animals were operated on with a rotating Knigge wire knife. The remainder received cuts with a nonrotating device that employed a strip of flexible razor material as a blade (Gillette Techmatic, $25 \mu \mathrm{m}$ thick $\times 850 \mu \mathrm{m}$ wide). The dorsal-ventral and rostral-caudal placement of cuts was varied and sham knife cuts involved lowering the knife tube into the brain without extruding the blade. After completing the knife cut procedure, a 23 gauge guide cannula was lowered into the brain so that the tip was embedded in preoptic tissue immediately ventral to the interventricular foramen. Jeweler's screws and dental cement were used to affix it to the skull. (Johnson and Epstein (1975) demonstrated that such a placement ensures reliable delivery of solutions into the ventricular space.)

Body weight and food and water intake. Body weights were recorded at the time of surgery and on the 3 subsequent days. During this time, water was provided in 100 -ml graduated cylinders outfitted with metal drinking spouts, and intake was measured to the nearest milliliter. Body weights and water intake were measured again for 3 days beginning on approximately the 31st day after surgery. Food intake was measured during the 24$\mathrm{hr}$ periods that preceded and followed the knife cuts and cannula implants. Spillage was collected on paper towels lying below the cage floor and was added to the uneaten food in calculating the amounts ingested.

Drinking tests. Approximately 1 week after surgery, drinking tests began. They were conducted in the home cage during the light period. Food was present and water was provided in a chemical burette outfitted with a metal drinking spout, allowing measurement of intake to the nearest $0.1 \mathrm{ml}$. Following subcutaneous injections and water deprivation periods, intake was recorded for $2 \mathrm{hr}$. When angiotensin was administered intracranially, drinking was monitored for $30 \mathrm{~min}$.

The first drinking test employed water deprivation as the thirst stimulus and involved the withholding of fluid for $24 \mathrm{hr}$ (followed by $2 \mathrm{hr}$ of recorded drinking), while food remained available. Three days later, a series of subcutaneous injections was initiated. These included injections of angiotensin (ANG) at doses of 1.5 and 3.0 $\mathrm{mg} / \mathrm{kg}(1 \mathrm{ml} / \mathrm{kg})$ and hypertonic saline (HYP) in concentrations of $4 \%$ and $12 \%$ and volumes of $1 \mathrm{ml} / 100 \mathrm{gm}$. Sham injections (poking under the skin with a "dry" 
needle) were given to control for base line rates of drinking. Consecutive injections were separated by approximately $24 \mathrm{hr}$ or more. They were administered in the following order: ANG, $3.0 \mathrm{mg} / \mathrm{kg}$; HYP, $12 \%$; ANG, 1.5 $\mathrm{mg} / \mathrm{kg}$; HYP, 4\%; sham; ANG, $1.5 \mathrm{mg} / \mathrm{kg}$; HYP, $12 \%$; HYP, $4 \%$; ANG, $3.0 \mathrm{mg} / \mathrm{kg}$; sham. After the last subcutaneous injection-drinking test, another 24-hr water deprivation test was conducted. Three days later, a control test for the water deprivation tests was conducted. This involved simply the measurement of intake for $2 \mathrm{hr}$ following $24 \mathrm{hr}$ of ad libitum food and water.

Next, animals were tested for drinking responses to intraventricular angiotensin $(50$ and $500 \mathrm{ng}$ in $2 \mu \mathrm{l}$ of bacteriostatic saline). Injector cannulas (same length as indwelling guide cannulas) were attached to microsyringes by approximately $0.5 \mathrm{~m}$ of PE-10 tubing. This system was filled with the solution to be injected, and the injector was inserted into the guide cannula. With the microsyringe attached to the front of the cage and a counterweight on the tubing to keep it out of reach, the animals were left undisturbed for $20 \mathrm{~min}$. Bolus injections then were given and intakes were recorded. A control procedure consisted of removal and replacement of the obturator. These tests were conducted on consecutive days in the following order: $500,50,500,50 \mathrm{ng}$, control.

Pressor tests. After completing all drinking tests, the animals were prepared for the measurement of pressor responses to intraventricular and intravenous angiotensin. Approximately $24 \mathrm{hr}$ before the testing session, rats were implanted with catheters (Microline) in the femoral artery and vein of one leg. These were sutured securely into the surrounding connective and muscle tissue and tunneled subcutaneously to the nape of the neck where they were exteriorized and flushed with heparinized saline (200 units/ml).

Pressor responses were recorded on a Beckman R612 polygraph through Ailtech transducers. Angiotensin that was injected intravenously was diluted to $2.4 \mu \mathrm{g} / \mathrm{ml}$ at the start of each test period from a refrigerated stock solution of $1 \mathrm{mg} / \mathrm{ml}$. The animal's intravenous line was flushed with this solution and then was connected to a $100-\mu$ l syringe by PE tubing containing the same mixture of angiotensin. This concentration allowed doses of 75 , 150 , and $300 \mathrm{ng} / \mathrm{kg}$ to be administered by varying the volume of the injection (e.g., a 400 -gm rat received injections of $12.5,25$, and $50 \mu \mathrm{l}$, respectively). (Injections of $100 \mu \mathrm{l}$ of saline in seven pilot animals produced no discernible pressor effect.)

Central injections of angiotensin were given in doses of 5,50 , and $250 \mathrm{ng} / \mathrm{rat}$. The solutions were mixed before this phase of the experiment began and were frozen in $0.5-\mathrm{ml}$ aliquots. Fresh samples were thawed at the start of each testing session. The delivery system for the intracranial injections (identical to that used for drinking tests) was filled with saline except for $2 \mu \mathrm{l}$ of drug at the end and a $0.5-\mu l$ bubble of air which separated the angiotensin solution from the saline. The tubing was rinsed thoroughly between injections.

Pressor responses were calculated by subtracting the base line level from the peak value that occurred during the 2 min following an injection. All scoring was done without knowledge of the animal's experimental condition.
Histology. At the completion of testing, all rats were anesthetized with ether and given a $2-\mu l$ injection of fast green dye via the intracranial implant. Rapid perfusion with saline and buffered formalin then was conducted. The brains from control animals were cut open transversely with a razor blade and gross examination was used to determine if the ventricular system was filled with dye as a test of the patency of the cannula system. The brains of experimental animals were embedded in an albumin/gelatin matrix (method of Fink and Kees, in Ebbesson, 1970). They were frozen to approximately $-25^{\circ} \mathrm{C}$ and sliced in $40-\mu \mathrm{m}$ sections in the sagittal plane, and the presence or absence of dye in the ventricles was noted at this time. Fifty serial sections, centered on the midline, were saved and every other one was stained with cresyl violet. Six of the remaining sections (the most medial three on either side of the midline) were stained with silver/pyridine for normal axons according to the protocol of Vogt (1974).

Statistics. Group data (mean \pm SEM) are presented graphically in Figures 4 to 6 . Significant differences were detected by analyses of variance. Interactions were followed by one-way analyses of variance for simple effects. Main effects for groups were analyzed with Duncan's multiple range test. The significance level for all tests was set at $\alpha=0.05$.

\section{Results}

Histological identification of groups. Examination of the histological material allowed the identification of three distinct groups of rats with horizontal knife cuts. One group $(n=10)$ had cuts immediately dorsal to the anterior commissure which severed both the precommissural and postcommissural connections between the SFO and the median preoptic nucleus (Figs. 1 and 2). In seven of these rats, the knife was lowered on the midline, anterior to the target, and in the other three, a lateral approach was taken. In addition to an interruption of the target fibers, these brains evidenced, to varying degrees, damage to the medial aspect of the columns of the fornix. It is likely, therefore, that some postcommissural SFO efferents bound for more caudal hypothalamic structures, as well as hippocampal connections, were included in these cuts.

A second group of animals $(n=7)$ had cuts along the rostral extreme of the anterior commissure (Figs. 1 and 2 ). These incisions interrupted the precommissural fibers that connect the SFO and the median preoptic nucleus. The postcommissural projections to the median preoptic and to more caudal, periventricular nuclei were undamaged. To be included in this group, intact fibers had to be present (as determined with the silver-stained material) in the position held by postcommissural SFO-median preoptic connections (Fig. 3). Besides an interruption of precommissural SFO efferents, these brains appeared to have varying amounts of damage to midline septal connections and to precommissural fibers of the stria terminalis.

A third group ( $n=8)$ had cuts that clearly missed the target pathway rostrally $(n=5)$ or laterally $(n=3)$. These animals (the "knife cut control group") were included in the following analyses as a control for the nonspecific effects of making a knife cut in the ventral 


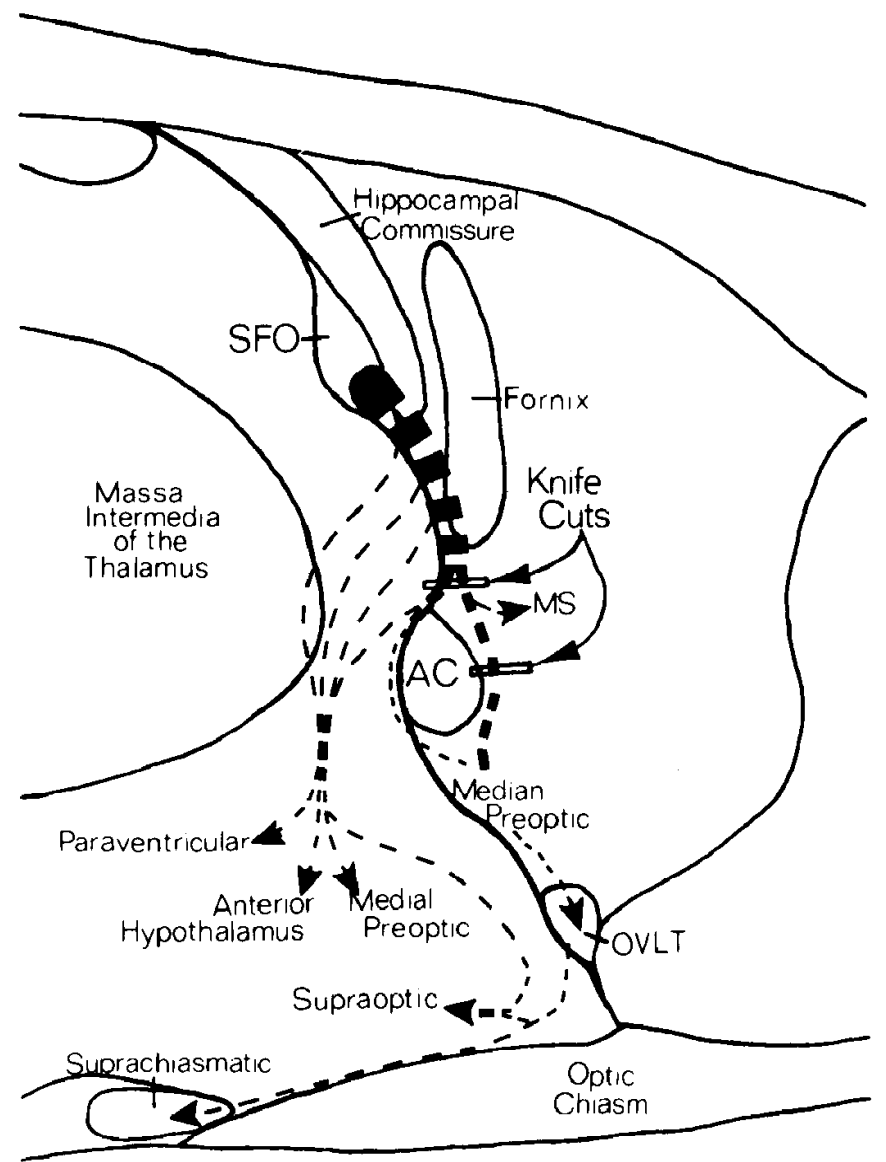

Figure 1. Schematic summary of SFO efferents (dashed lines) in the sagittal plane. The approximate size and position of knife cuts rostral to and dorsal to the anterior commissure $(A C)$ are shown. $M S$, Medial septum; OVIT, organum vasculosum of the lamina terminalis; SFO, subfornical organ.

forebrain. Another control group (the "sham control group," $n=12$ ) had the knife tube lowered into their brains at the same coordinates that were used for the experimental animals, but the blade was not extruded. All animals included in the following comparisons manifested patent intraventricular cannulas as evidenced by the presence of green dye throughout their ventricles.

Drinking responses. The responses to the various thirst stimuli are presented in Figure 4. In the first panel, the responses to water deprivation and the control test are shown. A general increase in responding on the second test was observed, but no group differences were found.

All animals received two injections of each of two doses of hypertonic saline, subcutaneous angiotensin, and intraventricular angiotensin. The two responses to the same dose of a given stimulus have been averaged for each subject, and these average scores were used in the statistical analyses and in calculating the group means. Drinking responses to all injected stimuli were significantly dose dependent (indicated by the main effects for dose).

Responses to hypertonic saline are shown in the second panel of Figure 4. The statistical tests indicated that the two experimental groups drank less than either control group at both doses and the experimental groups did not differ from each other. The slope of the dose-response curve for the experimental groups was less steep than that of the control groups (significant groups by dose interaction).

In the third panel of Figure 4, drinking responses following subcutaneous injections of angiotensin are presented. At both the low and high dose, the rats with knife cuts above the anterior commissure $(\boldsymbol{\Delta})$ drank significantly less than the rats with cuts rostral to the commissure $(\triangle)$, and both of these experimental groups drank less than the two control groups (which did not differ from each other). The slope of the dose-response curve for the experimental groups was less steep than that of the control groups.

Drinking responses to intraventricular angiotensin are presented in the fourth panel of Figure 4. The animals with cuts above the anterior commissure drank significantly less than the other three groups at both doses; no other group differences were found. No differences were detected in dose-response curve slopes.

Pressor responses. Dose-dependent pressor responses to angiotensin were elicited with each route of administration. In the left panel of Figure 5, the results from the intravenous injections are shown and it is clear that the groups did not differ. When angiotensin was injected intraventricularly (Fig. 5, right), rats in the sham control group $(O)$ responded with significantly greater increases in blood pressure than the other three groups.

Body weight and food and water intake. Figure 6 presents the measures of $24-\mathrm{hr}$ water intake and body weight at the time of surgery and 1 month later. The amount of water drunk was significantly reduced on day 1 postsurgery, but the groups did not differ from each other. The body weights also were diminished significantly following brain surgery and a significant group difference was detected. However, the absence of a significant interaction indicates that the differences in the body weights of the groups were not a function of surgery but rather were present at the time of surgery and persisted until the end of the study.

The amounts eaten by the four groups during the 24$\mathrm{hr}$ periods that preceded and followed the brain surgery are presented in Table $I$. The amount eaten on the night following the operation declined significantly but to a similar extent for the four groups.

\section{Discussion}

The present study tests the hypothesis that afferents to the ventral (or subcommissural) median preoptic nucleus (a component of the AV3V region) from angiotensin-sensitive cells in the SFO are important for the drinking response to circulating angiotensin. Rats with cuts of both pre- and postcommissural connections between these two nuclei had a nearly complete loss of the drinking response to peripheral angiotensin. Selective interruption of precommissural fibers produced a less marked, but significant, reduction. The findings are clearly consistent with the hypothesis and implicate both pre- and postcommissural fibers. 


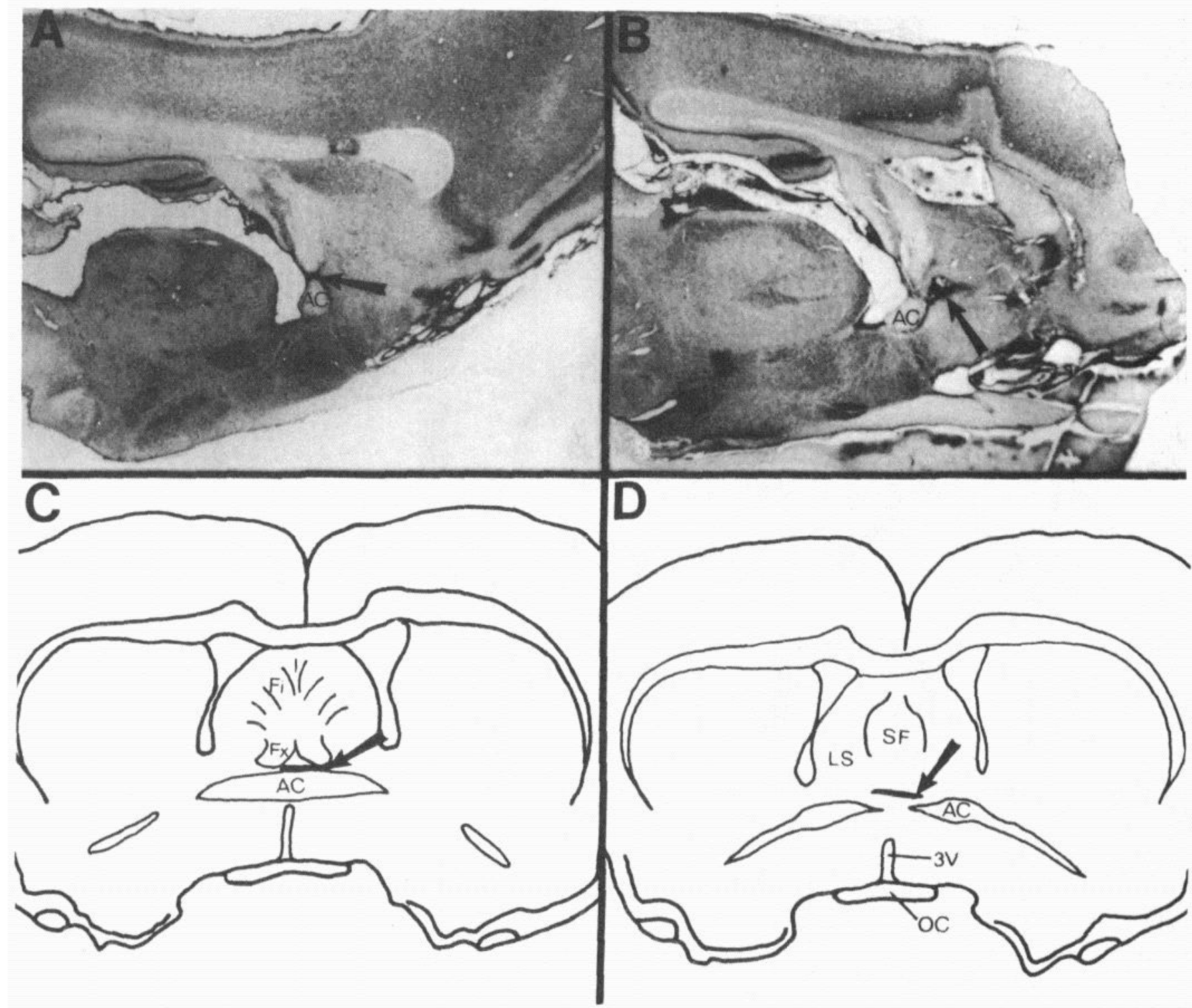

Figure 2. Sagittal views of knife cuts (arrows) dorsal $(A)$ and rostral $(B)$ to the anterior commissure. The lesion shown in $A$ is reconstructed in the coronal plane in $C$, and $B$ is reconstructed in $D$. $A C$, Anterior commissure; $F i$, fimbria; $F x$, columns of the fornix; $L S$, lateral septum; $O C$, optic chiasm; $S F$, septofimbrial nucleus; $3 V$, third ventricle. Magnification $\times 10$.

Although small and selective lesions were attempted, both knife cut placements included more than neural connections between the SFO and the ventral median preoptic nucleus. Therefore, at least three alternative explanations of the data must be considered. First, the OVLT receives neural inputs from the SFO via fibers traversing the median preoptic nucleus (Miselis et al., 1979; Lind et al., 1982) and these connections probably were included in both of the presently used knife cuts. Also included in these cuts, most likely, were connections between the OVLT and dorsal limbic structures (Camacho and Phillips, 1981). However, we have failed consistently to detect any attenuation of angiotensin-induced drinking with large OVLT lesions (Lind et al., 1979; Lind and Johnson, 1982a; Shrager and Johnson, 1980). Furthermore, we have observed that horizontal knife cuts just dorsal to the OVLT do not diminish drinking responses to peripherally administered angiotensin (Lind and Johnson, 1982b). Thus, if the OVLT and its dorsally directed neural connections participate in the dipsogenic action of angiotensin (Landas et al., 1980 ), their role appears to be minor.

Second, the septal complex has been shown to contain angiotensin-sensitive cells (Simonnet et al., 1980) and the present knife cuts may have severed connections related to them (Swanson and Cowan, 1979). However, large septal lesions do not diminish the drinking response to angiotensin administration (Black and Mogenson, 1973; Tondat and Almli, 1975) but, rather, may enhance the response (Blass et al., 1974).

Third, considerable evidence implicates the medial preoptic area in the dipsogenic action of angiotensin (see Swanson and Mogenson, 1981, for a review) and this area has bidirectional neural connections with the SFO (Mis- 

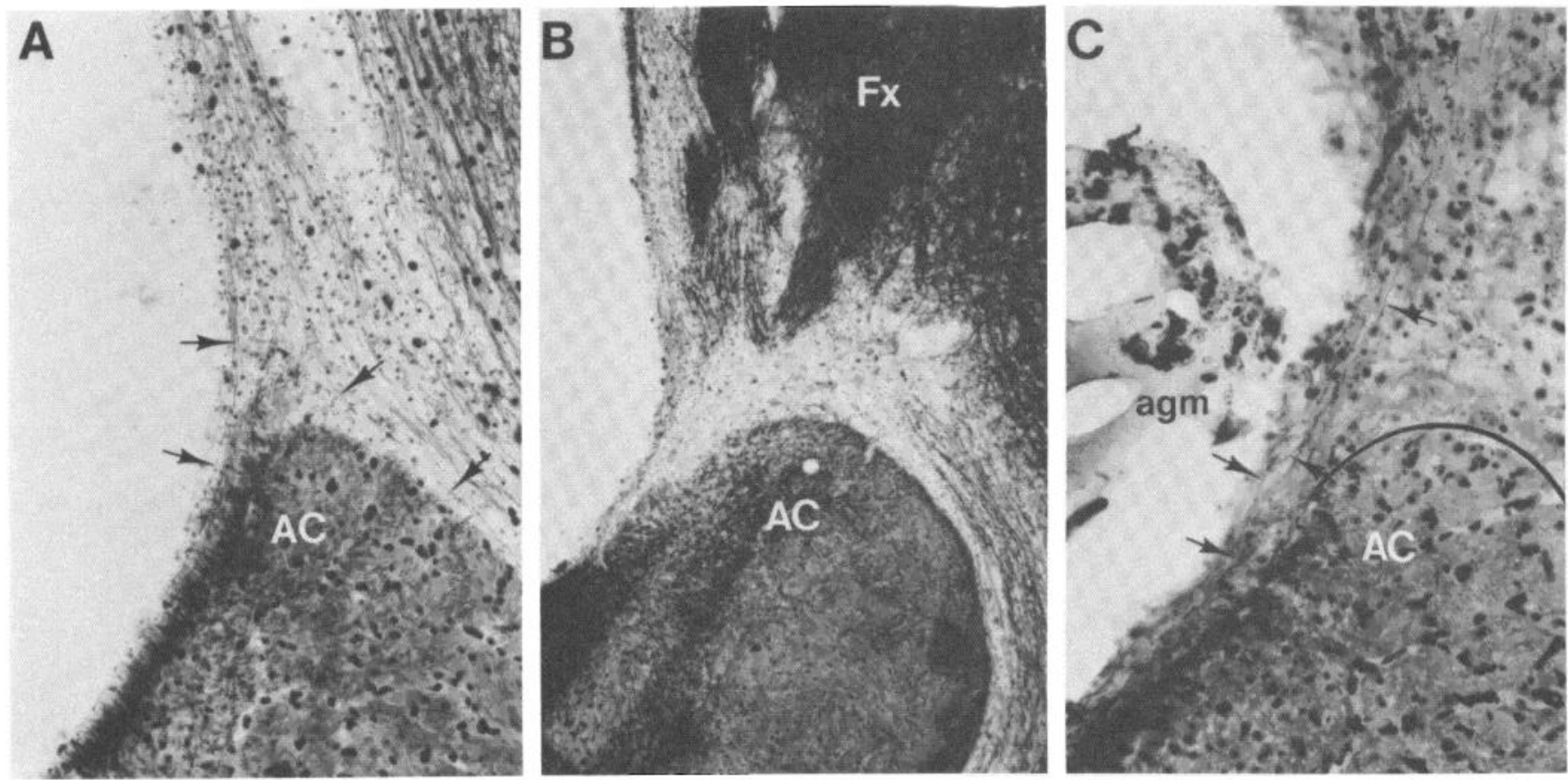

Figure 3. Silver-stained material showing fibers (arrows) in the position held by connections of the SFO. A, Pre- and postcommissural fibers are present in an animal from the sham control group. Magnification $\times 90$. B, This section was adjacent to the one shown in Figure $2 A$ and illustrates a conspicuous absence of pre- and postcommissural fibers in a rat with a cut dorsal to the anterior commissure. Magnification $\times 90$. $C$, This section was adjacent to the one shown in Figure $2 B$ and illustrates intact postcommissural fibers in an animal with a knife cut rostral to the anterior commissure (the dorsal border of the anterior commissure has been drawn in). Magnification $\times 225$. $A C$, Anterior commissure; agm, albumin/gelatin matrix; $F X$, columns of the fornix.
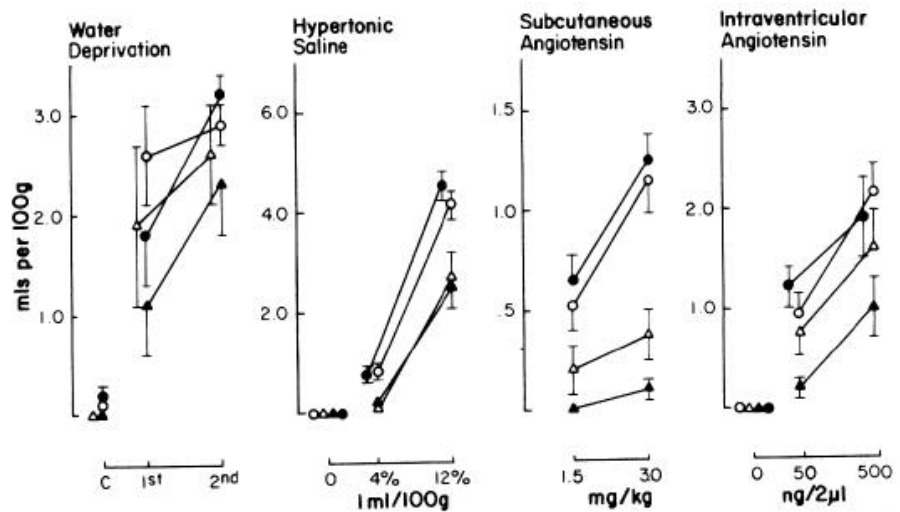

Figure 4. Responses of thirst stimuli. The amounts ingested have been converted to milliliters per $100 \mathrm{gm}$ of body weight. $\Delta$, Cuts above the anterior commissure; $\Delta$, cuts rostral to the anterior commissure; $\bullet$, knife cut control group; $\bigcirc$, sham control group.

elis et al., 1979; Lind et al., 1982). However, few, if any, of these fibers would have been included in the precommissural knife cuts which significantly reduced the drinking response to peripheral angiotensin. Furthermore, large electrolytic lesions of the medial preoptic area, which do not include the median preoptic nucleus, do not diminish the drinking response to circulating angiotensin (Lind et al., 1981).

It would appear, therefore, that the present knife cuts did not suppress drinking responses to circulating angiotensin by interrupting neural connections of the OVLT, the septal complex, or the medial preoptic area. Rather, since it has been shown that lesions of the SFO (Simpson
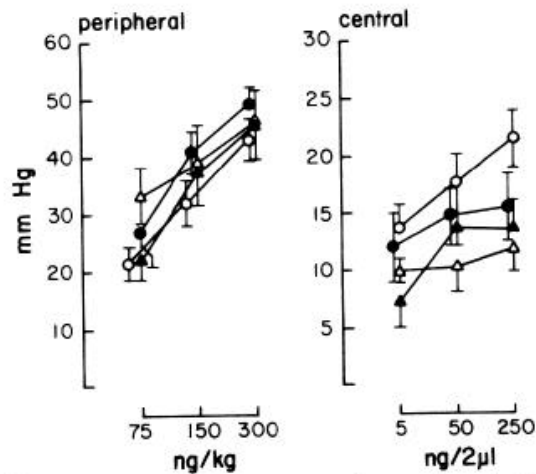

Figure 5. Pressor responses to angiotensin. $\boldsymbol{\Delta}$, Cuts above the anterior commissure; $\Delta$, cuts rostral to the anterior commissure; , knife cut control group; $\bigcirc$, sham control group.

and Routtenberg, 1975) and of the median preoptic nucleus (Lind et al., 1981; Mangiapane et al., 1981) do diminish angiotensin-induced drinking, the most parsimonious explanation of the present results is that the neural connections between these two areas also participate in the mediation of the response. The wealth of data implicating the SFO as the central site of action of circulating angiotensin (see the introduction) suggests that neural information relevant to thirst flows from the SFO to the median preoptic nucleus.

Lesions of the SFO and the AV3V region, and knife cuts between them, disrupt several other aspects of fluid balance and some of these functions were examined in the present experimental animals in order to determine the specificity of the knife cut effects. For example, knife cuts in the region of the ventral stalk of the SFO, which 

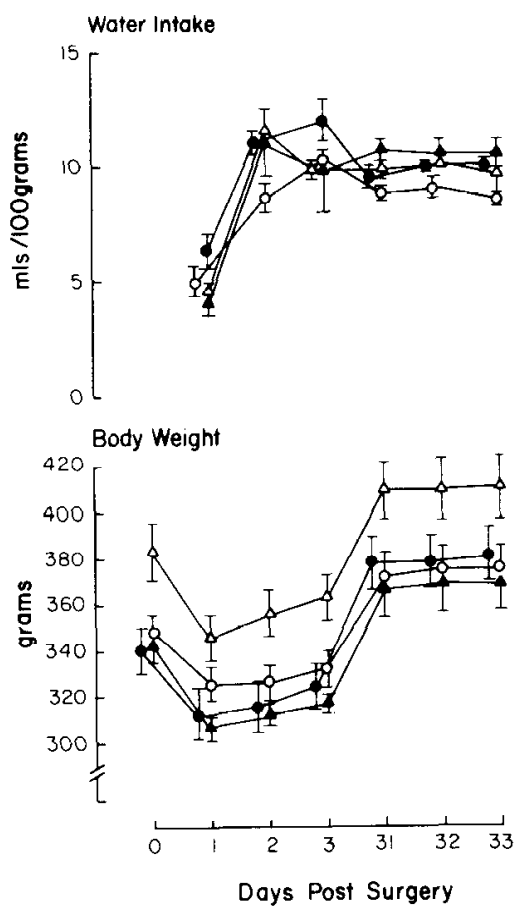

Figure 6. Water intake (top) and body weight (bottom) of the four groups following surgery. The body weight measure on day 0 represents the values taken at the time of surgery. $\Delta$, Cuts above the anterior commissure; $\Delta$, cuts rostral to the anterior commissure; 0 , knife cut control group; $\mathrm{O}$, sham control group.

TABLE I

Food intake during the $24 \mathrm{hr}$ before and after surgery

\begin{tabular}{lcc}
\hline Group & Before & After \\
\hline $\begin{array}{l}\text { Cuts above anterior } \\
\quad \text { commissure }\end{array}$ & $4.8 \pm 0.2^{b}$ & $3.6 \pm 0.4$ \\
$\begin{array}{l}\text { Cuts rostral to ante- } \\
\quad \text { rior commisure }\end{array}$ & $4.8 \pm 0.2$ & $2.5 \pm 0.8$ \\
$\begin{array}{l}\text { Sham knife cut con- } \\
\quad \text { trols }\end{array}$ & $4.5 \pm 0.2$ & $4.3 \pm 0.4$ \\
Knife cut controls & $4.4 \pm 0.1$ & $3.8 \pm 0.7$ \\
\hline
\end{tabular}

"Intakes have been converted to grams eaten per $100 \mathrm{gm}$ of body weight.

${ }^{b}$ Mean \pm SEM.

would sever nearly all SFO efferents, have been reported to produce polydipsia (Eng and Miselis, 1981). No increase in daily water intake was observed in the present animals, nor was there any evidence for acute postlesion adipsia that is characteristic of rats with electrolytic lesions of the AV3V region (Johnson and Buggy, 1978).

It is well established that lesions of the AV3V region disrupt osmotic thirst (Buggy and Johnson, 1977; Lind et al., 1979; Shrager and Johnson, 1980) and recent experiments suggest that the median preoptic nucleus may be especially important (Gardiner et al., 1981; Lind et al., 1981; Mangiapane et al., 1981). Thrasher et al. (1980) have suggested that the central osmoreceptors related to drinking reside within one or more of the circumventricular organs and several recent lesion studies have found reduced drinking responses to hypertonic saline injections in rats with lesions of the SFO (Hosutt et al., 1981; Saad and de Arruda Camargo, 1980; Shrager and John- son, 1980; Thunhorst et al., 1981) or knife cuts of its ventral stalk (Eng and Miselis, 1981). These findings are all consistent with the hypothesis that osmoreceptors in the SFO send information to the median preoptic nucleus for the initiation of drinking. However, a direct test of this hypothesis produced negative results (Buranarugsa and Hubbard, 1979) and underscores the need for a precise localization of cerebral osmoreceptors.

In view of the findings that responses to both angiotensin and hypertonic saline were diminished in the present study, it might be argued that a nonspecific failure to respond to thirst challenges had been induced by the knife cuts. This hypothesis is made unlikely, however, by the approximately normal drinking responses to intraventricular angiotensin by animals with cuts along the rostral extreme of the anterior commissure. If the reductions in responding that these animals showed when they were given subcutaneous injections were nonspecific effects, a similar attenuation would be expected with intraventricular angiotensin.

The failure to detect a group difference in responding to water deprivation also argues against the nonspecificity hypothesis. Examination of Figure 4 indicates, however, that, while no significant group difference was detected, the animals with cuts of both the pre- and postcommissural fibers $(\mathbf{A})$ tended to drink less than the other animals. The most likely explanation for this trend is that an animal that is relatively insensitive to the dipsogenic properties of hyperosmotic stimulation and increased titers of angiotensin also would be expected to under-respond when presented with a compound stimulus (i.e., water deprivation) that includes these two stimuli (Mann et al., 1980).

The partial reduction in drinking responses to intraventricular angiotensin by rats with cuts above the anterior commissure suggests that the pre- and postcommissural fibers between the SFO and the median preoptic nucleus are active in this type of thirst. This is a problematic finding since much evidence suggests that angiotensin that is injected into the cerebral ventricular system does not elicit thirst by stimulating receptors in the SFO (see Lind and Johnson, 1982a, for a review). It has been suggested, rather, that intraventricularly injected angiotensin, as well as the brain isorenin-angiotensin system, stimulates thirst by contacting receptors in the median preoptic nucleus (Lind and Johnson, 1982a). It may be that efferent information from these receptors is blocked by knife cuts above the anterior commissure.

Alternatively, this reduction in drinking when angiotensin was injected into the ventricles may have resulted from an interruption of SFO-median preoptic connections. According to this explanation, intraventricular angiotensin produces a small part of its dipsogenic effect by penetrating the ependyma covering the SFO in order to reach the same receptors that are stimulated by the peripheral route. A clearer interpretation of this effect awaits a more precise localization of receptors for cerebrospinal fluid-borne angiotensin.

The failure to observe attenuated pressor responses with intravenous injections of angiotensin distinguishes the present experimental animals from rats with AV3V lesions and from rats with lesions of the SFO. Likewise, the experimental rats appear to differ from rats with 
AV3V lesions in manifesting intraventricular angiotensin-induced pressor increases that were indistinguishable from the responses of the knife cut control group. Thus, it appears that the connections between the SFO and the median preoptic nucleus (or any other fibers interrupted by these knife cuts) are not crucial for the central pressor action of angiotensin by either route.

To summarize, the present results are consistent with the hypothesis that circulating angiotensin elicits thirst by stimulating receptors in the SFO. The subsequent excitation is transmitted over axons that pass on either side of the anterior commissure en route to the median preoptic nucleus. This substrate also may play a role in thirst that is initiated by subcutaneous hypertonic saline and, to a lesser degree, by intraventricular angiotensin. It does not appear to be necessary for the hypertensive effects of angiotensin by the peripheral or central routes. Thus, the present results constitute a functional separation of neural substrates that mediate the dipsogenic, as opposed to the pressor, action of circulating angiotensin.

\section{References}

Abdelaal, A. E., S. Y. Assaf, J. Kucharczyk, and G. J. Mogenson (1974) Effect of ablation of the subfornical organ on water intake elicited by systemically administered angiotensin-II. Can. J. Physiol. Pharmacol. 52: 1217-1220.

Black, S. L., and G. J. Mogenson (1973) The regulation of serum sodium in septal lesioned rats: A test of two hypotheses. Physiol. Behav. 10: 379-384.

Blass, E. M., A. I. Nussbaum, and D. G. Hanson (1974) Septal hyperdipsia: Specific enhancement of drinking to angiotensin in rats. J. Comp. Physiol. Psychol. 87: 422-439.

Brody, M. J., and A. K. Johnson (1980) Role of the anteroventral third ventricle (AV3V) region in fluid and electrolyte balance, arterial pressure regulation, and hypertension. In Frontiers in Neuroendocrinology, L. Martini and W. F. Ganong, eds., Vol. 6, pp. 249-292, Raven Press, New York.

Buggy, J., and A. E. Fisher (1976) Anteroventral third ventricle site of action for angiotensin induced thirst. Pharmacol. Biochem. Behav. 4: 651-660.

Buggy, J., and A. K. Johnson (1977) Preoptic-hypothalamic periventricular lesions: Thirst deficits and hypernatremia. Am. J. Physiol. 233: R44-R52.

Buggy, J., G. D. Fink, A. K. Johnson, and M. J. Brody (1977) Prevention of the development of renal hypertension by anteroventral third ventricular tissue lesions. Circ. Res. 40: I110-I117.

Buranarugsa, P., and J. I. Hubbard (1979) The neuronal organization of the rat subfornical organ in vitro and a test of the osmo- and morphine-receptor hypotheses. J. Physiol. (Lond.) 291: 101-116.

Camacho, A., and M. I. Phillips (1981) Horseradish peroxidase sludy in rat of the neural connections of the organum vasculosum of the lamina terminalis. Neurosci. Lett. 25: 201-204.

Ebbesson, S. O. E. (1970) The selective silver-impregnation of degenerating axons and their synaptic endings in non-mammalian species. In Contemporary Research Methods in Neuroanatomy, W. J. H. Nauta and S. O. E. Ebbesson, eds., pp. 157-158, Springer, New York.

Eng, R., and R. R. Miselis (1981) Polydipsia and abolition of angiotensin-induced drinking after transections of subfornical organ efferent projections in the rat. Brain Res. 225: 200-206.

Findlay, A. L. R., R. M. Elfont, and A. N. Epstein (1980) The site of the dipsogenic action of angiotensin II in the North American opossum. Brain Res. 198: 85-94.
Gardiner, T. W., M. L. Mangiapane, and J. B. Simpson (1981) Lesions of nucleus medianus but not organum vasculosum produce adipsia and thirst deficits in rats. Soc. Neurosci. Abstr. 7: 168.

Grazi, V. M., and R. R. Miselis (1980) Afferent and efferent projections of the nucleus medianus: An HRP study. Soc. Neurosci. Abstr. 6: 126.

Hernesniemi, J., E. Kawana, H. Bruppacher, and C. Sandri (1972) Afferent connections of the subfornical organ and of the supraoptic crest. Acta Anat. (Basel) 81: 321-336.

Hoffman, W. E., and M. I. Phillips (1976) Regional study of cerebral ventricle sensitive sites to angiotensin II. Brain Res. 110: 313-330.

Hosutt, J. A., N. Rowland, and E. M. Stricker (1981) Impaired drinking responses of rats with lesions of the subfornical organ. J. Comp. Physiol. Psychol. 95: 104-113.

Johnson, A. K., and J. Buggy (1978) Periventricular preoptichypothalamus is vital for thirst and normal water economy. Am. J. Physiol. 234: R122-R129.

Johnson, A. K., and A. N. Epstein (1975) The cerebral ventricles as the avenue for the dipsogenic action of intracranial angiotensin. Brain Res. 86: 399-418.

Landas, S., M. I. Phillips, J. F. Stamler, and M. K. Raizada (1980) Visualization of specific angiotensin II binding sites in the brain by fluorescent microscopy. Science 210: 791-793.

Lind, H. M., R. W. Lind, E. E. Shrager, S. L. Bealer, and A. K. Johnson (1979) Critical tissues within the periventricular region of the antero-ventral third ventricle (AV3V) associated with specific thirst deficits. Soc. Neurosci. Abstr. 5: 220.

Lind, R. W., and A. K. Johnson (1980) Knife cuts between the subfornical organ (SFO) and the antero-ventral third ventricle (AV3V) block drinking to peripheral angiotensin II. Soc. Neurosci. Abstr. 6: 33.

Lind, R. W., and A. K. Johnson (1981) Periventricular preoptichypothalamic lesions: Effects on isoproterenol-induced thirst. Pharmacol. Biochem. Behav. 15: 563-565.

Lind, R. W., and A. K. Johnson (1982a) Central and peripheral mechanisms mediating angiotensin-induced thirst. In The Renin Angiotensin System in the Brain, D. Ganten, M. Printz, M. I. Phillips, and B. A. Schölkens, eds., pp. 353-364, Springer-Verlag, New York.

Lind, R. W., and A. K. Johnson (1982b) On the separation of functions mediated by the AV3V region. Peptides (Fayetteville) 3: in press.

Lind, R. W., D. K. Hartle, M. J. Brody, and A. K. Johnson (1981) Separation of the functional deficits induced by lesions of the AV3V. Fed. Proc. 40: 390.

Lind, R. W., G. W. Van Hoesen, and A. K. Johnson (1982) An HRP study of the connections of the subfornical organ of the rat. J. Comp. Neurol. 211: in press.

Mangiapane, M. L., and J. B. Simpson (1980a) Subfornical organ lesions reduce the pressor effect of systemic angiotensin II. Neuroendocrinology 31: 380-384.

Mangiapane, M. L., and J. B. Simpson (1980b) Subfornical organ: Forebrain site of pressor and dipsogenic action of angiotensin II. Am. J. Physiol. 239: R382-R389.

Mangiapane, M. L., T. Gardiner, and J. B. Simpson (1981) Hypertonic saline- and angiotensin-induced drinking is blocked by destruction of dorsal nucleus medianus. Soc. Neurosci. Abstr. 7: 264.

Mann, J. F. E., A. K. Johnson, and D. Ganten (1980) Plasma angiotensin II: Dipsogenic levels and angiotensin-generating capacity of renin. Am. J. Physiol. 238: R372-R377.

Miselis, R. R. (1981) The efferent projections of the subfornical organ of the rat: A circumventricular organ within a neural network subserving water balance. Brain Res. 230: in press.

Miselis, R. R., R. E. Shapiro, and P. J. Hand (1979) Subfornical organ efferents to neural systems for control of body water. Science 205: 1022-1025. 
Saad, W. A., and I. A. de Armuda Camargo (1980) Interaction between the lateral preoptic area and the subfornical organ in the control of water ingestion caused by cellular dehydration, hypotension, hypovolemia, and deprivation. Behav. Neural Biol. 28: 138-149.

Shrager, E. E., and A. K. Johnson (1980) Contributions of periventricular structures of the rostral third ventricle to the maintenance of drinking responses to humoral dipsogens and body fluid homeostasis. Soc. Neurosci. Abstr. 6: 128.

Simonnet, G., B. Bioulac, F. Rodriguez, and J. D. Vincent (1980) Evidence of a direct action of angiotensin II on neurones in the septum and in the medial preoptic area. Pharmacol. Biochem. Behav. 13: 359-363.

Simpson, J. B. (1981) The circumventricular organs and the central actions of angiotensin. Neuroendocrinology 32: 248-256.

Simpson, J. B., and A. Routtenberg (1973) Subfornical organ: Site of drinking elicitation by angiotensin. Science 181: 1172-1175.

Simpson, J. B., and A. Routtenberg (1975) Subfornical organ lesions reduce intravenous angiotensin-induced drinking. Brain Res. 88: 154-161.
Simpson, J. B., A. N. Epstein, and J. S. Camardo, Jr. (1978) Localization of receptors for the dipsogenic action of angiotensin II in the subfornical organ of the rat. J. Comp. Physiol. Psychol. 92: 581-601.

Swanson, L. W., and W. M. Cowan (1979) The connections of the septal region in the rat. J. Comp. Neurol. 186: 621-656.

Swanson, L. W., and G. J. Mogenson (1981) Neural mechanisms for the functional coupling of autonomic, endocrine, and somatomotor responses in adaptive behavior. Brain Res. Rev. 3: 1-34.

Thrasher, T. N., C. J. Brown, L. C. Keil, and D. J. Ramsay (1980) Thirst and vasopressin release in the dog: An osmoreceptor or sodium receptor mechanism? Am. J. Physiol. 238: R333-R339.

Thunhorst, R. L., R. W. Lind, and A. K. Johnson (1981) Lesions of the subfornical organ (SFO) block drinking to peripheral but not central angiotensin. Soc. Neurosci. Abstr. 7: 638 .

Tondat, L. M., and C. R. Almli (1975) Hyperdipsia produced by severing ventral septal fiber systems. Physiol. Behav. 15: 701-706.

Vogt, B. A. (1974) A reduced silver stain for normal axons in the central nervous system. Physiol. Behav. 13: 837-840. 